\title{
SOBRE A ABORDAGEM DIREITO E POLÍTICAS PÚBLICAS (DPP) EM UM CURSO DE GRADUAÇÃO EM DIREITO: CONTRIBUIÇÃO CRÍTICA PARA A CONSTRUÇÃO DE UM PROGRAMA
}

\section{ABOUT THE LAW AND PUBLIC POLICY APPROACH (LPP) IN A LAW UNDERGRADUATION COURSE: A CRITICAL CONTRIBUTION TO A PROGRAM}

EMILIANO R. BRUNET ${ }^{1}$

RESUMO: O presente artigo procura debater criticamente desafios específicos implicados na construção de um programa de ensino de políticas públicas no contexto de um curso de graduação em direito, como é aquele da Faculdade Nacional de Direito da FND/UFRJ. Adota-se, como ponto de partida, a peculiar institucionalização do debate sobre políticas públicas no meio jurídico, do que decorre a relevância da indagação sobre a contribuição específica que o direito teria a aportar ao tema. Pondera-se que essa condição impõe ao docente e pesquisador o desafio de refletir sobre uma estratégia de abordagem do tema. Em diálogo com traços estruturais do curso da FND/UFRJ e das opções que levaram à própria criação da disciplina "Políticas Públicas e Inclusão Social", o artigo busca explicitar os desafios inerentes a uma estratégia articulada a partir de dois eixos: (i) o investimento na dimensão interdisciplinar como algo compatível e, a depender do método empregado, sinérgico ao desenvolvimento de uma reflexão jurídica sobre políticas públicas; (ii) o valor heurístico de uma abordagem que projete o debate acerca de direito e políticas públicas sobre o pano de fundo histórico das transformações do Estado e das instituições. Objetiva-se, ainda, apontar determinadas questões epistemológicas que se apresentam para a montagem de um programa que contemple esses eixos, buscando, sempre que possível, fazê-lo em diálogo com os caminhos que vêm sendo explorados por autores que têm se debruçado sobre a construção de uma abordagem de Direito e Políticas Públicas (DPP).

Palavras-Chave: Direito e Políticas Públicas; Abordagem e método; Estudos interdisciplinares; Ensino Jurídico.

\footnotetext{
${ }^{1}$ Professor da Faculdade Nacional de Direito da UFRJ. Doutor em Ciência Política pelo IESP-UERJ. Contato: brunet.emiliano@gmail.com. http://lattes.cnpq.br/8520406366813912. ORCID 0000-00015157-8775.
} 
ABSTRACT: This article critically discusses specific challenges involved in the construction of a public policy teaching program in the context of an undergraduate law course, such as that of the National Faculty of Law (FND / UFRJ). As a starting point, the peculiar institutionalization of the debate on public policies in the legal environment is adopted, from which follows the relevance of the question about the specific contribution that the Law and Public Policy (LPP) approach would offer regarding the overmentioned theme. It is considered that this condition imposes on the professor and researcher the challenge of reflecting on a strategy to approach the theme. In dialogue with structural features of the FND / UFRJ course and the options that led to the very creation of the discipline "Public Policies and Social Inclusion", the article seeks to explain the challenges inherent in a strategy articulated from two axes: (i) the investment in the interdisciplinary dimension as compatible and, depending on the method employed, synergistic to the development of a legal reflection on public policies; (ii) the heuristic value of an approach that projects the debate about law and public policy against the historical background of the transformations of state and institutions. It also aims to point out certain epistemological questions that are presented for the setting up of a program that contemplates these axes, seeking, whenever possible, to do so in dialogue with the paths that have been explored by authors who have focused on construction of a Law and Public Policy (LPP) approach.

Keywords: Law and Public Policy - Approach and Method - Interdisciplinary Studies - Legal Teaching.

\section{INTRODUÇÃO}

O presente artigo tem por objeto o exame de determinados desafios específicos que se colocam para a elaboração de uma agenda de ensino e pesquisa de políticas públicas no âmbito de um curso de graduação em direito, como é o caso daquele da Faculdade Nacional de Direito (FND) da UFRJ. Partindo do peculiar percurso de institucionalização acadêmica do tema no meio jurídico, pretendemos examinar tais desafios em diálogo com o esforço teórico e metodológico que vem sendo empreendido em busca do desvelamento da contribuição específica que o direito teria a aportar ao estudo de políticas públicas (BUCCI, 2013; CAILLOSSE, 2000). 
Assumimos que a perquirição da eventual especificidade de uma contribuição analítica e metodológica sobre políticas públicas erigida a partir do direito não deve desconhecer que juristas e cientistas políticos experimentam contiguidades e aproximações em suas respectivas abordagens, notadamente em função de interrogações fundamentais sobre um objeto que lhes é comum, qual seja, o Estado, sua natureza, características e forma de ação (RENARD, 2000).

Nesse diapasão, o próprio interesse pelo estudo de políticas públicas e a institucionalização acadêmica desse tema têm como pano de fundo e são responsivos às transformações por que passou o Estado brasileiro, notadamente a partir da transição à democracia e com o advento da Constituição Federal de 1988, processo este intensificado, já sob a égide da estabilidade político-democrática, pela profusa legislação materializadora do programa constitucional, bem como pelos correlatos (e obviamente não lineares) desenvolvimento de capacidades institucionais visando à materialização de objetivos politicamente pactuados e proliferação de programas governamentais nos diversos níveis federativos.

Encontra-se bem estabelecido que, na esteira do aprofundamento das transformações acima mencionadas, a análise de políticas públicas, embora presente enquanto Grupo de Trabalho na Associação Nacional de Pós-Graduação em Ciências Sociais (ANPOCS) desde meados dos anos 1980 (ARRETCHE, 2003), conheceu, no Brasil, um mais forte e acelerado processo de institucionalização acadêmica no final da primeira década dos anos 2000 (BRASIL; CAPELLA, 2016).

A criação de novos cursos de políticas públicas (ou ainda, de gestão de políticas) constituiria um dos indicadores do processo acima referido, sendo destacada por Carlos Aurélio Pimenta de Faria nos seguintes termos:

no caso do conhecimento acadêmico sobre as políticas públicas no Brasil, devem-se ressaltar, dentre tantas outras evidências da grande centralidade assumida pelo campo no país, os diversos novos cursos de graduação dedicados às políticas públicas ou à gestão pública, espalhados por todo o país. Vários desses novos cursos assumem plena e abertamente o caráter interdisciplinar desse campo do saber. (FARIA, 2013, p. 19).

Há dois aspectos presentes no excerto anterior que, a nosso sentir, merecem ser explorados para os propósitos do presente artigo, a saber, a ênfase no caráter interdisciplinar presente em boa parte dos cursos identificados por Faria e a necessidade de contextualização e problematização da sugestão de que o processo de institucionalização acadêmica antes referido participe ou contribua necessariamente para a formação de um campo ou subcampo do saber. Ambos os aspectos nos permitirão melhor situar os desafios específicos concernentes à construção de uma agenda de ensino e pesquisa de políticas públicas no âmbito 
de um curso de graduação em direito como o da Faculdade Nacional de Direito (FND) da UFRJ.

\title{
II. INSTITUIÇÃO DA DISCIPLINA POLÍTICAS PÚBLICAS E INCLUSÃO SOCIAL NO CURSO DE DIREITO DA FND. CONTEXTUALIZAÇÃO DOS DESAFIOS DAÍ DERIVADOS
}

Figurando como disciplina obrigatória de recente inclusão no curso de graduação em direito da FND e estando, portanto, inserida na vaga de institucionalização acadêmica a que vimos nos referindo, a disciplina "Políticas Públicas e Inclusão Social" nasce, segundo se infere claramente do Projeto Pedagógico do Curso - PPC (UFRJ/FND, 2012), sob o signo da interdisciplinaridade. Em rigor, o Projeto Pedagógico da FND elege o tema "Direitos Humanos e Inclusão Social" como seu eixo norteador e aponta a interdisciplinaridade como uma de suas duas diretrizes didático-pedagógicas, esta última sugestivamente definida no documento como "a base de uma compreensão ampliada do Direito, por meio da qual torna-se possível uma visão crítica e propositiva em face à própria dogmática jurídica" (BRASIL, 2012, p. 34).

Por esse ângulo, se a perspectiva interdisciplinar vem sendo defendida como horizonte epistemológico na abordagem de políticas públicas (FARIA, 2013, p. 21), no caso da disciplina "Políticas Públicas e Inclusão Social" no âmbito da FND ela materializa, expressa e textualmente, também uma diretriz institucional.

Para além disso, ainda segundo o Projeto Pedagógico do curso de direito da FND, espera-se e sinaliza-se que a interdisciplinaridade seja mobilizada não apenas na abordagem da disciplina "Políticas Públicas e Inclusão Social" em si mesma, como também constitua um horizonte de diálogo e integração entre esta e as disciplinas do curso como um todo. A este propósito, confira-se a seguinte passagem do PPC do curso de direito da FND:

\begin{abstract}
as ementas, conteúdos programáticos e bibliografias das disciplinas são concebidos como instâncias curriculares voltadas permanentemente para a necessidade de integração curricular por meio da adoção da cultura da interdisciplinaridade. A interdisciplinaridade consiste, portanto, numa opção estrutural do Curso (BRASIL, 2012, p. 34; grifamos).
\end{abstract}

Assim, se bem examinado, o documento aponta a possibilidade de construção de uma agenda de ensino e pesquisa de políticas públicas na FND convergente, em alguma medida, com uma das vertentes metodológicas sugeridas por Maria Paula Dallari Bucci (2019), qual seja, aquela que destaca o potencial de evolução 
de uma abordagem de Direito e Políticas Públicas que, embora não dê azo, por si mesma, à formação de um campo específico, tenha em mira, do ponto de vista metodológico, o diálogo e revisitação de temas tradicionais dos campos já estabelecidos no âmbito jurídico.

Tal observação nos leva ao segundo aspecto presente no excerto do artigo de Carlos Aurélio Pimenta de Faria anteriormente colacionado, igualmente relevante para os propósitos do presente artigo. Referimo-nos ao fato de que a aceleração do processo de institucionalização acadêmica do estudo de políticas públicas embora bem definidos seu contexto histórico e seu substrato político e social - não se deu nem poderia se dar de forma homogênea em todas as áreas do conhecimento.

Com efeito, o corpus conceitual e teórico, o instrumental analítico e a própria estrutura do discurso científico legitimado e estabelecido em cada área normalmente resultantes de processos de longa duração e de disputas no âmbito do próprio campo do direito (BOURDIEU, 2012) ${ }^{2}$ - influenciam não apenas sua maior ou menor porosidade ao tema políticas públicas, como também os próprios mecanismos de assimilação desse tema e das novas questões e desafios, tanto científicos quanto políticos, a ele correlatos.

Isto implica uma incontornável heterogeneidade inerente à assimilação do tema políticas públicas no seio de cada área do conhecimento (como a administração, a economia ou o direito), razão pela qual o processo de institucionalização acadêmica do estudo de políticas públicas não é necessariamente subsumido pela formação de campos ou subcampos deste saber no interior de cada disciplina ${ }^{3}$.

Não se ignoram as posições acadêmicas que identificam a Análise de Políticas Públicas (APP) como um campo específico, dotado de objeto próprio e ferramental teórico-analítico discernível, em que pese constituído sob o signo da

\footnotetext{
${ }^{2}$ Vale conferir, na obra citada, a fina e percuciente descrição de Bourdieu acerca do modo como as disputas no assim denominado "campo administrativo" - com larga e intensiva mobilização do direito e de seu discurso, técnicas e procedimentos - explicam a mudança da política pública habitacional em França, nos anos 1970, de um paradigma baseado na construção de moradias do tipo HLM (Habitation à Loyer Moderé), com financiamento público, a um paradigma baseado na criação de um mercado de financiamento individual da aquisição de moradia (BOURDIEU, 2012, p. 31-45).

${ }^{3}$ Cabe aqui aclarar uma diferença importante. Como mencionado na nota anterior, o exame acurado das disputas no campo estatal ou administrativo constitui uma moldura analítica profícua, a nosso juízo, para o estudo das políticas públicas. É certo - e nesse ponto alinhamo-nos à análise bourdiesiana - que o direito não se transforma mecanicamente, ou ainda, de maneira estritamente funcional às transformações sociais e econômicas, constituindo um capital específico, segundo Bourdieu (2012), mobilizado em tais disputas. Estas últimas, como visto na nota acima, podem dizer respeito, por exemplo, ao paradigma de uma determinada política pública. Isto não significa, todavia, e este é ponto a ser destacado no corpo do texto, que a mobilização do direito no contexto de tais disputas leve à formação, no interior do direito enquanto área de conhecimento, de um subcampo ou de uma subárea de políticas públicas.
} 
interdisciplinaridade (FARIA, 2013). Tampouco se desconhecem as análises que postulam que o estudo de políticas públicas configuraria um subcampo ou subárea, particularmente no âmbito da ciência política (ARRETCHE, 2003), ou ainda posições como a defendida por Brasil e Capella (2016) no sentido de que o estudo de políticas públicas constituiria um "campo epistemológico", multidisciplinarmente formado em diálogo com "áreas mais tradicionais" como a ciência política e a administração pública.

Partindo-se precisamente do ponto suscitado pelos últimos autores citados é que nos parece mais produtivo examinar o processo através do qual o interesse por políticas públicas emerge em cada contexto disciplinar e, nesse passo, ao suscitar perguntas específicas, interpela a linguagem e os conceitos assentados e constituídos. Noutros termos, para além do debate sobre a constituição de um campo disciplinar autônomo, mostra-se relevante observar como o processo antes referido pode levar ao desenvolvimento de novas abordagens e, dialeticamente, propiciar tanto o incremento do conhecimento sobre o modo específico de atuação estatal que denominamos "políticas públicas" como, de outra banda, o próprio arejamento dos saberes tradicionais em cada área.

Veja-se, à guisa de exemplo comparativo, que na área de Administração Pública o despertar de um olhar acadêmico mais sistemático para o tema de políticas públicas remontaria, no Brasil, ao final da década de 1960, com forte protagonismo da EBAP e da Revista de Administração Pública (FARAH, 2013).

No caso acima, tal movimento de assimilação do debate sobre políticas públicas, não obstante sincrônico com o que o ocorria no mesmo período nos Estados Unidos, certamente não seria infenso, na linha do que destacamos acima, ao peso da tradição e da formação histórica da área de conhecimento da Administração Pública no Brasil, fortemente influenciada, em suas origens, pelo viés da administração científica e pelo seu caráter aplicado ${ }^{4}$. Voltava-se, pois, a reflexão da área de Administração Pública, em suas origens, à formação e ao treinamento da burocracia - do que a criação do DASP constituiria o exemplo histórico mais eloquente, dentre tantos outros -, donde decorre sua coevolução, ao menos desde os anos 1930, com o próprio processo de modernização e reformas do Estado brasileiro (FARAH, 2013; LIMA JÚNIOR, 1998; WAHRLICH, 1984).

Com isto queremos enfatizar que, se é possível perquirir a eventual contribuição da área disciplinar da Administração Pública para o estudo e análise de políticas públicas, o êxito de tal perquirição não pode ignorar, como o demonstra Marta Farah (2013), que a emergência de um objeto de investigação ou

\footnotetext{
${ }^{4}$ Tal viés, segundo Farah (2013), ecoaria, na origem e nas primeiras evoluções da disciplina Administração Pública no Brasil, não apenas um compromisso com o propósito de erigir uma aparelho administrativo moderno, como também uma tentativa de emancipação e demarcação vis à vis da "gramática política" herdada de um período em que a "Administração Pública no Brasil tendia a se identificar com o Direito Administrativo" (FARAH, 2013, p. 108-109).
} 
mesmo de um novo campo ou subcampo suscitam uma necessária contextualização histórica e a devida atenção ao modo como a tradição se articula ou é tensionada por esse novo objeto.

Por esse prisma, voltando à questão da elaboração de uma agenda de ensino e pesquisa de políticas públicas no contexto de um curso de direito, parece-nos sumamente relevante - para além da discussão sobre a questionável constituição de um subcampo ou de uma subárea de políticas públicas dentro do direito, ou ainda, sobre a eventual participação do direito na construção de um campo transdisciplinar - o exame do tensionamento e, consequentemente, dos desafios, inclusive metodológicos, que a emergência do tema políticas públicas suscita face ao saber jurídico tradicional.

Bem a propósito do que se vem de sustentar, vale trazer a lume eloquente passagem de Jacques Caillosse:

propor uma abertura pelo viés do direito na teoria das políticas públicas pressupõe sejam satisfeitas determinadas exigências metodológicas. Dentre elas, o alargamento do campo da juridicidade para além dos limites que lhe são tradicionalmente atribuídos pela doutrina jurídica. Será necessário, efetivamente, tratar o jurídico à maneira de um material político (...). A se insistir no impasse sobre a dimensão jurídica das políticas públicas, nos privamos de uma ferramenta de conhecimento essencial5. (CAILLOSSE, 2000, p. 29; grifamos).

A ideia de um alargamento do campo da juridicidade se mostra profícua na medida em que descortina um horizonte de reflexão acerca do modo como a relação entre direito e políticas públicas é fortemente constituída por uma tensão que diz respeito à questão das fronteiras ou limites entre direito e política, bem assim entre direito e economia.

A noção de alargamento ou ampliação do campo da juridicidade, nessa toada, conserva aquela tensão na medida em que, se por um lado faz ver que a delimitação do campo jurídico é, em si mesma, política e sensível às transformações históricas e sociais, por outro reconhece a especificidade do fenômeno na medida em que o direito e o pensamento jurídico não apenas assimilam conceitual e discursivamente aqueles estímulos como também

\footnotetext{
${ }^{5}$ Tradução livre do original em francês, assim redigido: "proposer une ouverture coté droit dans la théorie des politiques publiques suppose de satisfaire certaines exigences méthodologiques. Parmi celles-ci, l'élargissement du champ de la juridicité, au delà des limites qui lui sont traditionellement assignées par la doctrine des juristes. Il sera necéssaire en effet de traiter le juridique à la manière d'un matériau politique. (...) À pratiquer l'impasse sur la dimension juridique des politiques publiques on se prive d'un outil de connaissance essentiel" (CAILLOSSE, 2000, p. 29).
} 
fornecem um léxico às mudanças, assim participando ativamente do processo que põe em movimento suas próprias fronteiras.

Por esse prisma, dois eixos nos parecem particularmente relevantes na construção de uma abordagem, na medida em que se complementam e jogam luz sobre o processo acima referido, a saber, o desafio da interdisciplinaridade e a análise das relações entre direito e políticas públicas em perspectiva histórica.

\section{UMA PROPOSTA BASEADA EM DOIS EIXOS: INTERDISCIPLINARIDADE E VIÉS HISTÓRICO}

\section{O desafio interdisciplinar: prospecção de alguns desdobramentos}

Como se extrai do tópico anterior, um dos principais desafios a serem enfrentados envolveria, portanto, a construção de uma estratégia de abordagem do tensionamento - de limites, categorias e esquemas mentais - que a emergência da temática de políticas públicas antepõe não apenas às disciplinas estabelecidas e ao pensamento jurídico tradicional, como também ao entrincheiramento do direito vis à vis de outros saberes. Em sintonia com a diretriz institucional do Projeto Pedagógico do curso de direito da FND, acreditamos que tal estratégia envolve a constante sustentação da tensão gerada pelo desafio da interdisciplinaridade.

Queremos com isso dizer que o compromisso com a interdisciplinaridade manteria no horizonte de nossa abordagem um duplo objetivo, tão complexo quanto crucial: o de evitar um fechamento do direito sobre si mesmo, mediante o constante escrutínio crítico de seu papel político, sem que, de outra banda, isto acarrete a desconsideração da especificidade do fenômeno jurídico e da contribuição peculiar e relevante que o direito teria a dar à abordagem de políticas públicas.

Entendemos que a sustentação da perspectiva interdisciplinar, nos termos acima, requer que o estudante de direito seja apresentado às principais conquistas e avanços teóricos produzidos a partir de outras áreas, como a ciência política em especial, bem como aos principais debates acadêmicos na seara de políticas públicas. Em outras palavras, para ficarmos com a expressão utilizada em conhecido trabalho de Celina Souza (2007), trata-se de buscar uma apropriação compatível com o aprofundamento possível e eficaz, do ponto de vista pedagógico, no contexto de um curso de direito ${ }^{6}$ do "estado da arte" do debate científico na área de políticas públicas.

\footnotetext{
${ }^{6}$ Esta avaliação, concernente à estratégia pedagógica de apresentação do sobredito debate, envolve um desafio peculiar no curso de direito da FND, uma vez que a disciplina "Políticas Públicas e Inclusão Social" é sinalizada, dentro da grade curricular normal do curso, como sendo obrigatória para discentes do $9^{0}$ período. Isto traz uma vantagem importante, que é a da possibilidade de revisitação de temas das disciplinas já estabelecidas, como o Direito Constitucional ou Administrativo, a discentes que já as cursaram. Mas, em contrapartida, tal
} 
Tal contato com o saber produzido acerca de políticas públicas em áreas como a ciência política acaba por "abrir", a nosso sentir, múltiplos veios de revisitação do conhecimento jurídico estabelecido, não apenas com o propósito de construir um (necessário) olhar crítico sobre o direito, mas também o de enfrentar o desafio, apontado por Diogo Coutinho, suscitado pela "proximidade (prática) e distância (acadêmica) entre o direito e o campo das políticas públicas" (COUTINHO, 2013, p. 183).

Como aponta o autor antes citado, embora sejam variadas as causas do aludido distanciamento, uma delas remonta à resiliência do formalismo e da estanqueidade de um ensino jurídico essencialmente focado em aspectos estruturais - e, segundo interpretamos a crítica de Coutinho (2013), em uma abordagem estática do fenômeno estatal e administrativo -, em detrimento de uma abordagem mais dinâmica e atenta ao "papel coordenador e articulador desempenhado pelo direito público e pelos juristas na modelagem institucional necessária à implementação de políticas" (COUTINHO, 2013, p. 184).

Embora atacando o problema a partir de uma posição que reivindicam como pertencente à "sociologia política do direito", Commaille e Dumoulin (2009) suscitam, face a determinados problemas contemporâneos da legalidade, inclusive os suscitados pela judicialização da política, a insuficiência heurística de um direito pensado em uma dimensão estática - à qual os autores aludem por meio da expressão "direito-referência" -, notadamente em face da possibilidade de um direito mobilizado cada vez mais frequentemente como ferramenta na construção e implementação de políticas - dimensão esta sinalizada pela expressão "direito- [como]recurso".

Quanto ao ponto, destacam os citados autores que a crescente presença do direito no universo das políticas públicas:

seria, então, uma das manifestações suscitadas pela tomada de consciência de uma modificação em curso no regime da legalidade (supranacionalização na produção das normas

configuração incrementa o desafio da interdisciplinaridade, haja vista a tendência a uma maior sedimentação da dogmática e dos esquemas teóricos e mentais específicos do direito entre alunos concluintes da graduação. É curioso notar que tal dilema se apresenta como uma "imagem invertida" do desafio abordado por Rizzi e Bambini (2019), haja vista que, no contexto acadêmico descrito por aqueles autores, têm-se normalmente um corpo discente já familiarizado, ao longo do ciclo básico da EACH/USP, com a perspectiva interdisciplinar e em contrapartida, ainda não versado em determinados conceitos fundamentais de direito. A complementaridade entre as perspectivas e vivências acadêmicas descritas por Rizzi e Bambini (2019) e aquelas apontadas no presente artigo só vem reforçar, a nosso juízo, a pertinência e até mesmo a imperatividade do esforço acadêmico em torno do desenvolvimento de uma metodologia de abordagem jurídica de políticas públicas que seja suficientemente aberta e integradora do direito às demais áreas do conhecimento sem deixar de manter no horizonte a pergunta sobre a especificidade da contribuição do pensamento jurídico. 
jurídicas e sua aplicação, proeminência cada vez mais acentuada e não importa quais sejam os sistemas de direito - romanogermânico ou common law - de um 'direito-recurso' em comparação com um 'direito-referência' $)^{7}$ (COMMAILLE e DUMOULIN, 2009, p. 101).

Compartilhando tais pontos de vista e críticas, pensamos que, sem a pretensão de exaurir ou recensear todas as possibilidades de interação entre o conhecimento produzido em outras áreas acerca de políticas públicas e o saber jurídico tradicional, muitos dos veios abertos a partir da apresentação do "estado da arte" do debate, por exemplo, na ciência política, podem conduzir a uma revisitação proveitosa do Direito Administrativo.

Com efeito, como aponta Coutinho no trabalho anteriormente citado, ainda predominaria no âmbito do administrativismo brasileiro uma visão fragmentária, como se percebe, por exemplo na abordagem e teorização estanque do "ato administrativo". Conquanto se trate de uma das construções mais emblemáticas da sedimentação histórica do direito administrativo, tal arcabouço teóricoconceitual, quando exposto ao desafio de descrever juridicamente uma política pública, tenderia antes a representá-la "como uma sucessão de atos administrativos, e não como um continuum articulado e dinâmico, estruturado em torno de fins previamente articulados a meios" (COUTINHO, 2013, p. 187).

A justificar a pegada interdisciplinar acima defendida, outros exemplos advindos da ciência política poderiam enriquecer a abordagem jurídica, ampliando e infundindo novas perspectivas críticas. Assim, debates clássicos em ciência política acerca da implementação de políticas públicas, como o proposto por Lipsky concernente à compreensão das condições e características da atuação da "burocracia do nível da rua", abrem uma produtiva discussão sobre temas caros ao direito administrativo, como os relativos à questão da autonomia e discricionariedade, seja sob a perspectiva de uma crítica das potencialidades e insuficiências da abordagem jurídica, seja como insumo para uma abordagem jurídica aplicada ao desenho e formulação de políticas públicas, eventualmente interessada no entendimento da funcionalidade ou disfuncionalidade - e dos problemas de coordenação e articulação aí implicados - de se alocar um maior ou menor grau de discricionariedade em mãos dos agentes públicos implementadores em nível local.

Como exemplo do caráter potencialmente profícuo do diálogo interdisciplinar em torno do tema mencionado no parágrafo anterior, merece atenção a análise proposta por Gabriela Lotta e Ariadne Santiago (2017) acerca das noções de autonomia e discricionariedade, notadamente por destacarem a dificuldade existente na construção de modelos mais consistentes e robustos de análise

7 Tradução livre do original em francês. 
empírica da atuação da burocracia, no contexto dos quais o emprego daqueles conceitos se mostre consequente e produtivo do ponto de vista do seu potencial explicativo. A superação de tal lacuna analítica, segundo as autoras, pressuporia o reconhecimento do uso indiscriminado e um esforço de especificação da polissemia observável na mobilização dos conceitos de autonomia $\mathrm{e}$ discricionariedade em variadas áreas do conhecimento, como o direito, a economia ou a ciência política (LOTTA; SANTIAGO, 2017).

A lacuna detectada e mencionada no trabalho antes citado parece, portanto, ratificar a necessidade de que, caso se deseje aprofundar e especificar a contribuição do pensamento jurídico na compreensão da ação das burocracias implementadoras de políticas públicas, o conhecimento tradicionalmente produzido no âmbito do direito administrativo acerca do conteúdo e dos limites da discricionariedade precisa ser cotejado e exposto ao arsenal teórico advindo de outras áreas disciplinares, seja como forma de se promover o cabível refinamento conceitual, seja como forma de se pôr à prova o potencial heurístico de noções que, como explicitam Lotta e Santiago, são efetivamente utilizadas com valências e propósitos diversos a depender do campo do qual provém a análise ${ }^{8}$.

Da mesma forma - e ainda à guisa de exemplo-, a discussão sobre capacidades estatais, bastante avançada hoje no domínio da ciência política, abre uma interessante janela sobre o direito público e, em particular, o direito administrativo. Veja-se que, segundo Alexandre Gomide e Roberto Pires, um dos temas centrais à configuração do debate sobre as capacidades estatais é aquele concernente aos arranjos institucionais.

Segundo Gomide e Pires:

\footnotetext{
${ }^{8}$ Note-se, por exemplo, apenas para ficarmos com a noção de discricionariedade, que, segundo Lotta e Santiago, "[o campo] jurídico considera a ideia de discricionariedade baseada na dimensão legal e de autoridade delegada. Para os autores dessa corrente, o uso de regras leva necessariamente à existência de discricionariedade, ao mesmo tempo em que a ideia desta pressupõe a existência de regras". Já, por exemplo, nos campos econômico e sociológico, respectivamente, a discussão sobre a discricionariedade estaria relacionada precipuamente "ao modelo de agente-principal" e ao uso da margem de apreciação "para realizar o julgamento das situações com que o burocrata lida, de forma que os agentes discricionários realizam seu papel reforçando a própria liberdade" (LOTTA; SANTIAGO, 2017, p. 23-24). No contexto da experiência docente, temos vislumbrado o potencial didático-pedagógico do exame concreto do papel de burocracias implementadoras no âmbito de políticas que tenham integrado a experiência de vida do discente, como, por exemplo, as políticas educacionais no âmbito do ensino médio. Tal abordagem permite discutir, apenas para citar um exemplo, o conceito de discricionariedade e autonomia à luz dos papéis exercidos pela figura do diretor escolar na implementação de políticas públicas bem delineadas, como o programa de alimentação escolar ou a Política Nacional do Livro Didático, notadamente em face da existência, nestas políticas, de componentes que envolvem margens de mediação, interação e decisão no nível local, isto é, no nível de cada comunidade escolar.
} 
o conceito de arranjo institucional entendido como conjunto de regras, mecanismos e processos que definem a forma particular como se coordenam atores e interesses na implementação de uma política pública específica. São os arranjos que dotam o Estado de capacidade de execução de seus objetivos. Ou, em outras palavras, são os arranjos que determinam a capacidade do Estado de implementar políticas públicas (GOMIDE; PIRES, 2014. P. 1920; grifamos).

Pois bem, a percuciente definição proposta por Gomide e Pires constitui um sonoro convite à reflexão sobre a correlação entre o direito (notadamente o direito público) e a estruturação, estabilização e desempenho de arranjos estatais. Tal ponto não escapou à análise de Bucci e Coutinho (2017), que chamam a atenção para a interlocução entre a tríade "capacidades estatais - arranjos institucionais direito" ao defenderem que os atributos do desenho institucional de uma determinada política pública "[tais] como o grau de descentralização, autonomia e coordenação federativa e intersetorial e os tipos de relações públicas e públicoprivadas que suscitam, bem como sua integração com outros programas, dependem, em larga medida, da consistência do arcabouço jurídico que as estrutura" (BUCCI; COUTINHO, 2017, p. 317).

Em relevante passagem acerca da correlação antes suscitada como ponto de apoio para uma abordagem interdisciplinar, Bucci e Coutinho afirmam ainda o seguinte, a propósito da interlocução entre direito e capacidades estatais:

o arcabouço jurídico, em outras palavras, disciplina a composição, o funcionamento e os limites de mudança de tais arranjos, os quais, por sua vez, disciplinam o emprego da capacidade estatal de implementar programas de governo (...) Assim, se as políticas públicas e seus arranjos particulares são em boa medida moldados e operados juridicamente, é possível dizer que o ângulo jurídico, tanto quanto o econômico, o sociológico, o antropológico e o de ciência política, é uma das "lentes" privilegiadas na observação, pela qual é possível identificá-los, analisá-los e modificá-los no curso da concepção, da implementação e da avaliação das ações governamentais. (BUCCI; COUTINHO, 2017, p. 317-318).

Por esse prisma, a discussão sobre os atributos técnicos e políticos de um determinado arranjo institucional lança no horizonte o desafio de exercitar uma reflexão sobre o direito público a partir de uma perspectiva dinâmica, que reserve espaço à avaliação, autocorreção e controle consequencialista dos referidos arranjos e, como corolário, dos papéis do direito. 
Ora, a adoção de tal perspectiva tende a colocar em xeque ou, no mínimo, a deslocar uma abordagem jurídica tradicional e acrítica que subsuma a descrição da Administração Pública à mera explicitação dos contornos de uma ordemquadro, cuja legitimidade é assumida ex ante, remetidas as indagações sobre suas implicações políticas e sociais ao universo de questões alheias ao direito 9 .

Ainda acerca dos atributos dos arranjos institucionais, vale notar que o conceito de capacidade estatal se desdobra nas vertentes da capacidade técnicoadministrativa e, eis o ponto a ser destacado, da capacidade política (GOMIDE; PIRES, 2014), o que, aprofundando a perspectiva que defendemos no parágrafo anterior, arrosta desde logo o risco de se reduzir a reflexão sobre os papéis do direito na constituição de arranjos institucionais ao viés estritamente funcional e tecnocrático da eficiência e do desempenho administrativos.

Por esse ângulo, a interdisciplinaridade, compreendida nos termos ora propostos, promove a compreensão de que o componente jurídico, para além da relevância da dimensão articuladora de arranjos institucionais coerentes e razoavelmente eficientes, também participa ativamente da garantia e promoção do caráter democrático do processo de formulação de implementação de políticas. Isto porque a capacidade política, elemento indissociável da noção mais ampla de capacidade estatal, pressupõe as aptidões institucionais para "a inclusão de múltiplos atores, o processamento dos conflitos decorrentes e a formação de coalizões políticas de suporte para os objetivos e as estratégias a serem adotadas". (GOMIDE; PIRES, 2014, p. 21).

Esta questão atinente à legitimação democrática constitui, aliás, um dos desafios que a abordagem Direito e Políticas Públicas ${ }^{10}$ se propõe a enfrentar, como se extrai da seguinte passagem:

Analisando arranjos jurídico-institucionais, a abordagem de Direito e Políticas Públicas pode valer-se da literatura estabelecida de análise institucional ao mesmo tempo em que não perde de vista seu objeto jurídico. Ao fazê-lo, cria mecanismos de "fertilização cruzada" com as demais ciências sociais analisando do ângulo jurídico, por exemplo, as dimensões técnica (efetividade) e política (legitimidade democrática) das políticas públicas. (BUCCI; COUTINHO, 2017, p. 324).

\footnotetext{
${ }^{9}$ Em trabalho seminal sobre as transformações do pensamento jurídico à luz de contextos políticosociais de incremento da complexidade e da interdependência das relações sociais no estágio atual do capitalismo, William Clune, bem a propósito da passagem supra, anota que um dos efeitos da aludida interdependência “(...) no pensamento jurídico é um novo requisito de performance - soluções legais devem funcionar (...) o direito não podendo permanecer ideologicamente indiferente aos seus efeitos" (CLUNE, 2011, p. 198; tradução livre do original em inglês).

10 Para uma visão abrangente e atualizada do método e aplicações da assim denominada abordagem de Direito e Políticas Públicas (DPP), confira-se Bucci (2019).
} 
Pela senda, portanto, do debate sobre capacidades estatais a abordagem interdisciplinar permite descortinar sobre o direito público um olhar pragmático e consequencialista, a partir do qual se podem interpelar, por exemplo, categorias como discricionariedade e vinculação, ou mesmo outros temas clássicos do direito administrativo, como os que dizem respeito à organização da Administração Pública, tanto do ponto de vista da coerência e aptidão técnico-administrativa de um determinado arranjo institucional, quanto do ponto de vista da sua legitimidade, é dizer, do seu caráter democrático ou da sua capacidade política, entendida nos termos acima explicitados.

\section{Valor heurístico da abordagem diacrônica: direito e políticas públicas em perspectiva histórica}

De forma articulada ao investimento pedagógico em uma perspectiva interdisciplinar, defendemos o potencial heurístico de um exame em perspectiva histórica do modo como a reflexão sobre políticas públicas, pari passu com as transformações experimentadas pelo Estado, passa a ocupar um lugar privilegiado no universo do direito.

Trata-se, inquestionavelmente, de fenômeno de origens políticas e sociais cuja adequada compreensão pode ajudar a romper os limites de uma abordagem simplificadora e acrítica do propalado processo de judicialização da política, bem como a jogar luz sobre o fato de que o contato entre direito e política não se dá apenas no contexto da atuação ordinária das instituições do sistema de justiça, mas também, e de forma decisiva, no processo de penetração do discurso, das técnicas e procedimentos do direito em outras arenas, do que a crescente processualização da atividade administrativa constituiria um exemplo contundente $^{11}$ (TATE; VALLINDER, 1995).

O exame do pano de fundo histórico de tais transformações deve servir ao propósito acadêmico e pedagógico de manter no horizonte a compreensão de que a relação entre direito e políticas públicas, além de não se reduzir ao teatro das instituições componentes do sistema de justiça, é sensível às transformações, especialmente no contexto da globalização, por que passaram e ainda passam o modo de produção capitalista e o Estado. Mais que isso, como observa agudamente William Clune (2011), as contradições inerentes ao desenvolvimento do modo de produção capitalista constituem o cenário ("landscape") no qual o direito está inevitavelmente encartado, de maneira que, ainda que as transformações deste revistam-se de um caráter multifacetado e não se subsumam funcional e instrumentalmente àquelas, tem-se na articulação entre as duas

${ }^{11}$ Fenômeno que Tate e Vallinder denominam sugestivamente judicialization from within. 
dimensões uma chave para a compreensão das transformações do próprio pensamento jurídico ${ }^{12}$.

Por essa via, a compreensão da ascensão e crise dos modelos de Estado de bemestar social, bem assim o escrutínio das transformações da democracia representativa (ROSANVALLON, 2008), são tão cruciais para a compreensão da relação entre direito e políticas públicas quanto para compreensão de seus dilemas e desafios em um momento de grave inflexão para as instituições que surgiram ao tempo da centralidade do mundo do trabalho e para o programa social inscrito na Constituição brasileira.

Abordando a questão a partir do caso francês, Caillosse assim se expressa acerca do ângulo analítico que encarece o exame das transformações do direito à luz das transformações do Estado, especialmente no contexto de crise do modelo de bem-estar social que fora o catalisador de uma atuação estatal galvanizada pela formulação e implementação em políticas públicas:

por meio das transformações da 'linguagem jurídica' se descobrem as novas imagens graças às quais o Estado, sob o influxo de políticas de modernização, não cessa de se atribuir uma identidade (...) [Trata-se] de observar, a partir do palco oferecido pelo direito, as operações jurídicas a que deve recorrer o Estado para obter a transformação de seus papéis: a grande passagem do Estado-providência ao Estado-regulador não se consumaria à base de um direito imutável. (CAILLOSSE, 2008, p. 225-226)

A partir do eixo aqui explorado, portanto, políticas públicas constituem uma forma de atuação estatal historicamente situada, que se afirma no contexto do segundo pós-guerra e da ascensão do Estado de bem-estar social. Tal contexto, para utilizarmos os termos de Przeworski (1985), é aquele de afirmação hegemônica do "capitalismo organizado" sob a fórmula do "compromisso

\footnotetext{
12 Pode-se encontrar no trabalho de Claus Offe uma formulação paradigmática e contundente do modo como o Estado Capitalista, abstraídas variações marginais na estrutura e função, corporifica uma determinada forma institucional do poder público em sua relação com a produção material, sendo a "política" de tal Estado o elemento dinâmico, isto é, as estratégias que produzem e reproduzem o acordo e a compatibilidade entre dimensões tais como a privatização da produção, a acumulação, o financiamento da máquina estatal através do sistema tributário e a legitimação democrática, esta última segundo a forma do governo democráticorepresentativo (OFFE; RONGE, 1984). Evidentemente, William Clune, no artigo citado, dialoga com as contradições estruturais inerentes ao funcionamento do Estado Capitalista tal como descrito por Offe. Comungamos da perspectiva de Clune segundo a qual, sem abrir mão da consideração das contradições intrínsecas à reprodução do Estado Capitalista como chave interpretativa, pode-se analisar tal processo - e, no contexto dele, as transformações do pensamento jurídico - sem necessariamente adotar-se uma perspectiva determinista e funcional (CLUNE, 2011, p. 195).
} 
keynesiano" no qual, afastado o horizonte revolucionário, o Estado assume funções gerais de regulação geral da economia e de provisão, por meio de políticas e programas governamentais, de condições para a criação e manutenção dos níveis de emprego, de mecanismos de assistência social, da expansão da atuação estatal, enfim, em diversos domínios, tais como habitação, saúde e educação, dentre outros.

Do ponto de vista das transformações institucionais, ainda segundo Przeworski (1985), este é um tempo em que uma imensa e variada gama de relações sociais passam a ser mediadas por instituições políticas democráticas, deslocando-se, assim, seu eixo gravitacional da esfera estritamente privada para a do compromisso entre as esferas política e econômica. Tal compromisso colocava no horizonte utópico do Estado Social, como nos adverte Habermas (2005 [1986]), não mais a libertação do "trabalho heteronômico", mas um equilíbrio que, ainda nutrindo-se dos "escombros da utopia da sociedade do trabalho", fosse supostamente capaz de "assegurar, através de intervenções estatais, uma coexistência pacífica entre capitalismo e democracia" (HABERMAS, 2005, p. 18).

As implicações do direito nessa arquitetura institucional são evidentes e uma abordagem atenta à correlação entre políticas públicas e o fenômeno jurídico deve ser capaz de reconhecer o peso histórico e o significado dessa imbricação. Ainda uma vez, devemos a Habermas a observação de que a reprodução dos sistemas econômico e político no contexto do modelo de bem-estar social - fincada na tessitura de formas de coexistência entre capitalismo e democracia - consumiu sobremaneira o "medium do poder", o que vale dizer, mobilizou intensamente tanto o direito (que se publicizou notavelmente) quanto o aparelho administrativo que lhe é correlato.

Eis as palavras de Habermas quanto ao ponto em questão:

O fato é que não se leva em conta qualquer ceticismo em relação ao 'medium' do poder, o qual talvez seja indispensável, mas talvez não seja inocente. Os programas do Estado social consomem grande quantidade dele, a fim de obter força de lei, financiados pelos erários públicos - e a fim de poderem ser implementados no mundo da vida dos seus beneficiários. Isso faz com que o dia-a-dia dos clientes reais e potenciais seja recoberto por uma rede cada vez mas densa de normas jurídicas e burocracias estatais e para-estatais. (HABERMAS, 2005, p. 22)

Dar a devida importância a uma abordagem histórica das relações entre direito e políticas públicas implica, portanto, assumir que o momento mesmo de afirmação desta última forma de atuação estatal está inserido em um contexto de, nas palavras de Habermas, "juridificação e burocratização em geral", compreendidos os dois termos como sinalizadores de um processo no qual a 
expansão da legislação disciplinadora da intervenção estatal nos domínios econômico e social - notadamente através de políticas e programas - se fez, em termos históricos, acompanhar do robustecimento e complexificação do aparelho administrativo incumbido de materializar aquele programa.

Uma das consequências do fenômeno expansivo da legislação disciplinadora da intervenção estatal nos domínios econômico e social acarretaria historicamente, segundo Cappelletti, num paradoxo por meio do qual o Legislativo se veria obrigado a abdicar ou delegar tarefas regulatórias essenciais em favor do Executivo. Segundo Cappelletti, os parlamentos:

\begin{abstract}
atribuíram-se tarefas tão numerosas e diversas que, para evitar a paralisia, encontraram-se ante a necessidade de transferir a outrem grande parte de sua atividade, de maneira que suas ambições terminaram em abdicação. E esses outros a quem a atividade foi transferida são principalmente, o executivo e seus órgãos derivados, com toda uma série de entidades e agencias a quem foram confiadas tarefas normativas e administrativas (...). Verifica-se, assim, (...) a transformação gradual do welfare state em Estado administrativo. (CAPPELLETTI, 1993, p. 43-44)
\end{abstract}

Assim, sob o prisma da observação histórica, a emergência do Estado de bemestar social e a progressiva expansão da intervenção estatal por meio de programas e políticas públicas constitui também um cenário de reconfiguração institucional das relações entre os Poderes e de transformação do direito, seja como medium de tal reconfiguração, seja como gramática de uma atuação burocrático-administrativa expandida, complexificada e, a um só tempo, juridicizada.

Recuperando a passagem de Jacques Caillosse anteriormente colacionada, a perspectiva histórica de abordagem das relações entre direito e politicas públicas aqui defendida permite descortinar o direito como palco, ou ainda, como veículo privilegiado de uma gramática política que entroniza, no contexto do Estado de bem-estar, uma atuação estatal acentuadamente organizada e estruturada sob a forma de programas ou políticas e, mais que isso, protagonizada em larga medida por aparelhos burocrático-administrativos cada vez mais complexos.

Abordando tal questão sob a perspectiva das contradições inerentes à reprodução do Welfare State e seu reflexo específico sobre o direito, William Clune, anota de forma percuciente o quanto segue:

o primeiro reflexo das contradições sociais sobre o direito é o problema do acesso a benefícios coletivos. O direito responde à crescente complexidade através do desenvolvimento de técnicas mais sofisticadas de planejamento social, frequentemente 
culminando na criação de estruturas administrativas concebidas para lidar com determinado problema social no interesse de determinado grupo de pessoas.(...) O problema do acesso surge com a questão dos 'requisitos'. Quase todo programa social suscita questões de 'pertencimento/requisitos' (dentro/fora) e estratificação interna ${ }^{13}$. (CLUNE, 2011, p. 200)

A transposição dessa moldura analítica mais geral para o caso brasileiro exige algum cuidado, mas não desvanece sua utilidade na compreensão do movimento geral e do ângulo a partir do qual se interpenetram a transformação do direito e dos próprios papéis do Estado. Isto porque, se as análises anteriormente colacionadas apontam para um processo simultâneo de juridicização e complexificação do maquinário burocrático-administrativo estatal, a passagem do Brasil à modernidade econômica e política - com a industrialização e a urbanização aceleradas a partir dos anos 1930 - não se fizeram sem um pesado investimento político no soerguimento do aparato administrativo estatal acompanhado de uma intensa mobilização dos mecanismos, procedimentos e da linguagem do direito ${ }^{14}$.

A imbricação do direito em tal processo não escapou à observação de Diogo Coutinho, conforme se vê na seguinte passagem:

Ao longo da história, o direito, incrustado em políticas econômicas e sociais, desempenhou distintos papéis na promoção de objetivos públicos, e as experiências e trajetórias nacionais do século XX ilustram momentos em que o arcabouço jurídico foi intensamente empregado pelo Estado para promover a modernização, o crescimento, a industrialização, o investimento e, de modo geral, mudanças estruturais (...). (COUTINHO, 2012, p. 79)

Uma abordagem de Direito e Políticas Públicas no Brasil deve, portanto, ser capaz de iluminar o modo como o direito participou historicamente da tessitura

\footnotetext{
${ }^{13}$ Tradução livre do original em inglês. No original, faz-se alusão à 'membership', ou à qualidade de membro, para referir-se ao problema da qualificação ou não ao recebimento de benefício ou à participação em determinado programa social. Em tradução livre, visando à preservação do sentido original, optou-se por "requisito" ou "pertencimento" para se manter a referência à ideia de estratificação interna e externa e de preenchimento ou não de condições para a fruição do benefício.

${ }^{14}$ Vejam-se, apenas para citar dois exemplos eloquentes, a regulação jurídica do processo eleitoral com o Código Eleitoral de 1932 e a tutela jurídica da cidadania por intermédio da regulação das relações de trabalho com a legislação trabalhista de 1937.
} 
da gramática política ${ }^{15}$ das relações entre Estado e sociedade. Para além disso, mostra-se particularmente produtiva a compreensão dessa relação à luz da polarização "atraso-moderno", o que vale dizer, a partir de uma chave explicativa que compreenda o direito como um dos principais artifícios através dos quais se construiu e se transformou, ao longo do tempo, uma trajetória de passagem à modernidade política e social.

O direito se apresenta, por esse prisma, como um campo fértil de investigação de determinadas continuidades e descontinuidades presentes em um processo histórico que, adotando-se a periodização e descrição propostas por Sonia Draibe (1993), teria sido marcado, entre os anos 1930-1964, por uma política social essencialmente focada no trabalhador assalariado urbano, fragmentada e seletiva em sua cobertura e objetivos.

Tal processo continuará a encontrar no direito seu léxico após 1964, período no qual o surgimento de sistemas públicos nas áreas de saúde, educação, assistência social e habitação (DRAIBE, 1993) não representará qualquer interpelação - mas antes aprofundamento - da modernização de viés conservador e centralizado, com pouco ou nenhum controle social e farta utilização de práticas clientelistas e de cooptação. Como observa Coutinho, "no período de 1964-1988 (...) o que há de mais perceptível é a instrumentalização do direito público - administrativo, financeiro, econômico - para a consecução de objetivos macroeconômicos". (COUTINHO, 2012, p. 88)

Para os fins da abordagem aqui proposta, tal andamento histórico de mudançaconservação amparado pelo direito virá efetivamente encontrar na transição democrática, que se inicia em $1974^{16}$ e desemboca no texto constitucional de 1988, um momento de particular inflexão (WERNECK VIANNA, 2008).

Para uma abordagem interessada na relação entre direito e políticas públicas, o período enfocado é representativo na medida em que transformações econômicas, sociais e políticas se precipitam e abrem espaço para - com o derruimento de determinadas bases do paradigma de modernização econômica centralizada e autoritária - uma transformação no padrão das relações entre Estado e sociedade. Tal mudança de padrão se traduz, a um só tempo, na abertura de uma via larga para a reflexão sobre a atuação estatal materializadora do programa constitucional por meio de políticas públicas e, mais que isso, para a reflexão sobre o papel do direito na estruturação de tal atuar em um ambiente democrático.

${ }^{15}$ Estamos aqui deliberadamente utilizando a locução "gramática política" em referência ao já clássico trabalho de Edson Nunes (1997).

16 Vale anotar que, após a crise do petróleo de 1973, acompanhada dos sinais de esgotamento do modelo autoritário de desenvolvimento econômico baseado na substituição de importações e, já em 1974, com fragorosa derrota da ditadura militar nas eleições para o Senado, começava a desenhar-se a inexorabilidade do retorno à democracia. 
Ainda explorando a pertinência de uma abordagem da relação entre direito e políticas públicas sob o viés histórico, o reformismo sob o governo Fernando Henrique Cardoso, com os esforços de reforma do aparelho da Administração Pública e a introdução do paradigma gerencialista, constitui um ângulo igualmente profícuo de análise. Sob forte protagonismo do Poder Executivo, com ênfase nos papéis da burocracia e por meio de uma intensa mobilização do direito e dos seus intelectuais, o "novo intervencionismo regulatório" (BOSCHI; LIMA, 2002) introduzido por aquela coalizão reformista deixaria marcas indeléveis na reflexão acerca dos papéis e do modo de atuação do Estado brasileiro por meio de políticas públicas.

Com efeito, no contexto da agenda e da ideologia reformista daquele período, interpenetram-se uma narrativa sobre as mudanças em escala global nos anos 1990, uma determinada interpretação sobre a formação histórica do Estado brasileiro e uma apreciação crítica acerca de nossa estrutura institucional, particularmente a político-administrativa. Trata-se, em suma, de um período que testemunha forte interpelação das relações entre direito e políticas públicas, inclusive da modelagem legada pela Constituição de 1988, principalmente com o incremento da circulação da retórica gerencialista e com a tendência à superdeterminação econômica ${ }^{17}$ dos objetivos e do próprio andamento das reformas (BRUNET, 2017).

\section{Conclusão}

Articulados pelo propósito de elaboração de uma estratégia de ensino e pesquisa de políticas públicas a partir do direito, os dois eixos explorados na seção anterior encontram na tensão inerente ao alargamento do campo da juridicidade o seu fil rouge. Na medida em que o lugar e significado do ensino e pesquisa de políticas públicas em um curso de direito constitui o ponto de partida da análise aqui desenvolvida, deve ficar claro que a interrogação sobre os papéis e transformações do direito acaba por conter, em si mesma, uma não menos relevante indagação sobre o próprio pensamento jurídico e, nessa linha, sobre a forma como tal pensamento se constitui, é legitimado e transmitido.

Em trabalho instigante acerca do significado político da estrutura curricular do ensino jurídico, Duncan Kennedy (1983) associara o desenvolvimento do Welfare State ao surgimento, nos cursos de direito, de novas disciplinas que incorporavam

\footnotetext{
17 Sobre o ponto da "superdeterminação econômica" das interpretações acerca dos papéis e da forma de atuação do Estado nos domínios econômico e social, Dezalay e Garth (2002), examinando o contexto da América Latina, assinalam que os anos 1990 teriam testemunhado a ascensão, no campo do poder estatal, de agentes que mobilizariam, como capital simbólico e como mecanismo de produção de representações sobre a remodelação do Estado, precipuamente o pensamento econômico mainstream.
} 
e, em certa medida, assimilavam o movimento de mudança social, política e econômica no contexto estadunidense.

O surgimento de tais disciplinas - dentre as quais os estudos interdisciplinares e os ramos do direito público associados à nova configuração políticoinstitucional pós New Deal - teria sustentado uma clivagem no âmbito da qual passaram a ser associadas ao componente doutrinário e mais tradicional do direito qualidades ligadas ao seu caráter supostamente mais sistêmico, integrado, racional e, sobretudo, neutro. Em contrapartida, à margem ou na periferia do componente doutrinário, segundo aquela ótica, teriam proliferado novas disciplinas supostamente menos integradas, dispersas, desprovidas de vigor sistêmico e, especialmente, politicamente orientadas à mudança.

A contribuição de Kennedy fornece, como fica claro, uma chave heuristicamente valiosa para a discussão do lugar e sentido do ensino e pesquisa de uma disciplina como "Políticas Públicas e inclusão social" em um curso de direito. Tal contributo reveste-se de ainda maior importância na medida em que Kennedy sugere a artificialidade da polarização acima descrita e das qualidades supostamente associadas ao núcleo doutrinário do direito, de um lado, e aos novos componentes curriculares responsivos às mudanças políticas e sociais, de outro. Isto porque, a reivindicação do caráter neutro e estritamente racional do componente doutrinário seria antes de mais nada uma reivindicação de conteúdo político facilmente demonstrável ${ }^{18}$.

Se a análise de Duncan Kennedy tem o mérito de explorar o componente político ínsito à estrutura curricular de ensino do direito e de iluminar a dialética que se estabelece entre a legitimação e transmissão do conhecimento jurídico e as transformações socioeconômicas e políticas, coube a Clune (2011) recuperar tal dinâmica sob a chave das tensões e contradições inerentes ao desenvolvimento do Estado capitalista, para fazer destas últimas o cenário no âmbito do qual se podem reexaminar e pôr a prova descontinuidades sobretudo aparentes entre o núcleo teórico tradicional do direito e os novos saberes jurídicos, ou ainda, nos termos do autor, entre "centro" e "periferia".

Sob este diapasão, Clune consegue propor uma abordagem no âmbito da qual "pensamento jurídico e economia política parecem não apenas similares, mas partes fortemente ligadas por uma mesma construção, uma imbricada na outra (...), com múltiplos pontos de convergência substantiva" (CLUNE, 2011, p. 194).

\footnotetext{
${ }^{18}$ Segundo Duncan Kennedy, a escolha de pontos de partida e a filiação a paradigmas (seja na doutrina sobre a proteção do direito de propriedade, seja na teoria sobre a liberdade contratual), assim como a contradição e o conflito também são inerentes ao componente doutrinário e lhe imprimem, igualmente, caráter político. Nesta chave, as próprias contradições intrínsecas ao componente doutrinário seriam ininteligíveis sem o concurso, por exemplo, dos estudos interdisciplinares. À guisa de exemplo, Kennedy aponta ser impossível identificar as contradições do direito privado sem conhecer e transmitir aos discentes o conhecimento sobre os paradigmas teóricos subjacentes e concorrentes acerca, por exemplo, do crescimento econômico (KENNEDY, 1983, p. 15).
} 
A partir desse ângulo de análise, é possível debater a polarização entre centro e periferia do conhecimento jurídico em outros termos. Assim, na medida em que, no cerne do desenvolvimento do Estado capitalista, competem e interagem projetos aparentemente conflitantes - arraigados na liberdade econômica, de um lado, e na inescapável interdependência social, de outro -, mostra-se possível enxergar os traços da participação do direito em ambos os projetos ${ }^{19}$ e, consequentemente, na interação dialética entre eles.

Desta forma, em lugar de um espaço vazio resultante da dicotomização entre centro e periferia do pensamento jurídico, ou ainda, da polarização entre o núcleo doutrinário e os estudos interdisciplinares, o que se descortina é um espaço no qual atuam forças centrífugas, como as que reorientam o direito a uma maior conexão com a realidade social e a análises do tipo "problem-solving", e forças centrípetas, que tendem a promover o fechamento do direito em torno de uma racionalidade indisputada por saberes concorrentes.

Um tema, enfim, que ressoa fortemente em ambas as análises acima citadas é aquele atinente à irresolvível tensão entre as pulsões de fechamento e abertura do direito, ou ainda, entre integração ou desintegração. Pensamos que esta tensão, em perspectiva dialética, somente poderá encontrar uma boa síntese se ela não implicar no sacrifício de uma pulsão em detrimento da outra. Em termos objetivos, tanto a percepção, em Kennedy (1983), do caráter político da legitimação e transmissão do conhecimento jurídico mesmo em seu núcleo doutrinário, quanto o reconhecimento, em Clune (2011), de que há antes um espaço de transição e recomposição do que propriamente de cisão entre os assim denominados centro e periferia do pensamento jurídico, encontram um ponto de possível síntese no já citado processo de alargamento ou ampliação do campo da juridicidade.

Nesta zona de transição ou recomposição, o campo do direito não apenas se expande como se transforma qualitativamente, como o demonstra a observação de Clune no sentido de que, em um contexto de complexificação e interdependência social e econômica, a análise jurídica tradicional continua relevante, mas "seu papel mudou e se tornou mais eclético" (CLUNE, 2011, p . 203). Sob tal chave, a tensão entre as pulsões aparentemente contraditórias acima mencionadas se resolve não na recusa ao contato com outros saberes $\mathrm{e}$ racionalidades concorrentes, mas sim no enfrentamento do desafio de prover, a partir do direito, sem descurar do rigor metodológico, uma contribuição política e socialmente responsiva aos desafios que a abordagem de políticas públicas suscita no Brasil contemporâneo.

Um desses pontos incontornáveis envolve, tanto sob a perspectiva metodológica quanto a da seleção dos temas e objetos de investigação científica,

${ }_{19}$ Sobre a participação essencial do direito na viabilização da dinâmica capitalista fundada na

"liberdade econômica", vale conferir o seminal trabalho de Katharina Pistor (2019). 
um olhar cuidadoso às transformações por que passam, nesta quadra, o pensamento jurídico e sua reprodução e transmissão.

Quanto à relevância de tal aspecto, merece atenção o notável estudo conduzido por Dezalay e Garth, baseado na análise do papel de juristas e economistas na reconfiguração do poder estatal na América Latina durante as últimas décadas do século XX. Ao abordarem o papel do pensamento jurídico e, sobretudo, dos mecanismos de estabilização, legitimação e transmissão desse pensamento na reprodução e transformação de hierarquias políticas e sociais, Dezalay e Garth puderam anotar o seguinte:

\begin{abstract}
A chave do estatuto do direito reside em sua relação com dois conjuntos de instituições estreitamente ligadas: a faculdade de direito e o Estado. As faculdades de direito desempenham um papel central na reprodução do saber e das elites no poder e, assim, também no sistema de hierarquização dessas elites, em função dos saberes e das competências que elas detém. Todo esforço de reforma do funcionamento ou do conteúdo do que é ensinado pelas faculdades de direito coloca em questão os equilíbrios de poder e as relações de dominação que estas instituições contribuem para legitimar e estabilizar. (DEZALAY; GARTH, 2002, p. 26-27) ${ }^{20}$.
\end{abstract}

Por esse ângulo, conclusivamente, a construção de um programa de ensino de direito e políticas públicas deve se apropriar criticamente do papel que o saber jurídico desempenha, reservando em sua agenda o devido espaço ao aprofundamento metodológico e ao refinamento das categorias propriamente jurídicas de análise das políticas públicas sem perder de vista que, dando-lhe peculiar conotação e sentido, tal esforço é empreendido em um contexto político e histórico de transformação das profissões, do pensamento e do ensino jurídicos. Os eixos interdisciplinar e histórico, tal como expostos neste trabalho, contribuem sobremaneira para iluminar os desafios à frente nesse caminho.

\title{
REFERÊNCIAS
}

ARRETCHE, Marta. Dossiê Agenda de pesquisa em políticas públicas. RBCS Revista Brasileira de Ciências Sociais, v. 18, n. 51, 2003, p. 07-09.

BOSCHI, Renato; LIMA, Maria Regina S. O Executivo e a construção do Estado no Brasil: do desmonte da Era Vargas ao Novo Intervencionismo Regulatório. In:

\footnotetext{
${ }^{20}$ Tradução livre do original em francês.
} 
WERNECK VIANNA, L. (Coord.). A Democracia e os Três Poderes no Brasil. Belo Horizonte: Ed. UFMG, 2002.

BOURDIEU, Pierre. Sur l'État. Cours au Collège de France. 1989-1992. Paris: Éditions du Seuil, 2012.

BRASIL. UFRJ/FND - Faculdade Nacional de Direito. Projeto Pedagógico de Curso, 2012. Disponível em: <http://www.direito.ufrj.br/images/stories/ direito Lgraduacao/documentos/PROJETO PEDAG\%C3\%93GICO FND 2014.pdf>. Acesso em: 03 dez. 2019.

BRASIL, Felipe Gonçalves; CAPELLA, Ana Claudia N. Os Estudos das Políticas Públicas no Brasil: Passado, Presente e Caminhos Futuros da Pesquisa Sobre Análise de Políticas. Revista Política Hoje, v. 25, n. 1, 2016.

BRUNET, Emiliano R. Reforma do Estado no Governo Fernando Henrique Cardoso (1995-2002). Ideologia reformista, economicismo e direito em uma época de mudanças. Rio de Janeiro: Lumen Juris, 2017.

BUCCI, Maria Paula Dallari. Método e aplicações da abordagem Direito e Políticas Públicas (DPP). Revista Estudos Institucionais, v. 5, n. 3, 2019.

BUCCI, Maria Paula Dallari. Fundamentos para uma teoria jurídica das políticas públicas. São Paulo: Saraiva, 2013.

BUCCI, Maria Paula Dallari; COUTINHO, Diogo. Arranjos jurídico-institucionais da política de inovação tecnológica: uma análise baseada na abordagem de direito e políticas públicas. In: COUTINHO, Diogo; FOSS, Maria Carolina; MOUALEM, Pedro Salomon (orgs.) Inovação no Brasil avanços e desafios jurídicos e institucionais. São Paulo: Blucher, 2017.

CAILLOSSE, Jacques. La constitution imaginaire de l'administration. Paris: Presses Universitaires de France (PUF), 2008.

CAILLOSSE, Jacques. Le droit comme méthode? Réflexions depuis le cas français. In: RENARD, Didier; CAILLOSSE, Jacques; DE BÉCHILLON, Denys. L'analyse des politiques publiques aux prises avec le droit. Paris: LGDJ, 2000.

CAPPELLETTI, Mauro. Juízes Legisladores? Porto Alegre: Sergio Fabris, 1993. 
COMAILLE, Jacques; DUMOULIN, Laurence. Heurs et malheurs de la légalité dans les sociétés contemporaines. Une sociologie politique de la judiciarisation. L'Année Sociologique, v. 59, n. 1, 2009 , p. 63-107.

COUTINHO, Diogo R. O direito nas políticas públicas. In: MARQUES, Eduardo; FARIA, Carlos Aurélio P. A Política Pública como Campo Multidisciplinar. São Paulo: UNESP, 2013.

COUTINHO, Diogo R. O direito nas políticas sociais brasileiras: um estudo sobre o Programa Bolsa Família. In: SCHAPIRO, Mario; TRUBEK, David M. (orgs.).

Direito e Desenvolvimento. Um diálogo entre os BRICS. São Paulo: Saraiva, 2012.

CLUNE, William. Legal Disintegration and a Theory of the State. German Law Journal, v. 12, n. 1, p. 186-205, 2011.

DEZALAY, Yves; GARTH, Bryant. La Mondialisation des Guerres de Palais. La restructuration du pouvoir d'État en Amerique Latine, entre notables du droit et “Chicago Boys". Paris: Seuil, 2002.

DRAIBE, Sonia M. Welfare State no Brasil: caracteristicas e perspectivas. In: 902 Universidade Estadual de Campinas (UNICAMP). Caderno de Pesquisas do Núcleo de Estudos de Políticas Públicas - NEPP. Caderno de Pesquisa no 8, 1993.

FARAH, Marta Ferreira S. A contribuição da Administração Pública para a constituição do campo de estudos de políticas públicas. In: MARQUES, Eduardo; FARIA, Carlos Aurélio P. A Política Pública como Campo Multidisciplinar. São Paulo: UNESP, 2013.

FARIA, Carlos Aurélio P. A multidisciplinaridade no estudo das políticas públicas. In: MARQUES, Eduardo; FARIA, Carlos Aurélio P. A Política Pública como Campo Multidisciplinar. São Paulo: UNESP, 2013.

GOMIDE, Alexandre A.; PIRES, Roberto Rocha. Capacidades estatais e democracia: abordagem dos arranjos institucionais para análise de políticas públicas. In: GOMIDE, Alexandre A.; PIRES, Roberto Rocha (orgs). Capacidades Estatais e Democracia. Arranjos Institucionais de Políticas Públicas. Brasília: IPEA, 2014. 
HABERMAS, Jürgen. A crise do Estado do Bem-Estar e esgotamento das energias utópicas. In: HABERMAS, Jürgen. Diagnósticos do Tempo. Seis Ensaios. Rio de Janeiro: Tempo Brasileiro, 2005.

KENNEDY, Duncan. The Political Significance of the Structure of the Law School Curriculum. Seton Hall Law Review, v. 14, n. 1, p. o1-16, 1983.

LIMA JUNIOR, Olavo Brasil de. As reformas administrativas no Brasil: modelos, sucessos e fracassos. Revista do Serviço Público, v. 49, n. 2, abr./jun., p. 05-32, 1998.

LOTTA, Gabriela; SANTIAGO, Ariadne. Autonomia e discricionariedade: matizando conceitos-chave para o estudo de burocracia. BIB, n. 83, 2017.

NUNES, Edson. A gramática política do Brasil - Clientelismo e Insulamento Burocrático. Rio de Janeiro: Garamond, 1997.

OFFE, Claus; RONGE, Volker. Teses sobre a fundamentação do conceito de "Estado Capitalista" e sobre a pesquisa política de orientação materialista. In: OFFE, Claus. Problemas Estruturais do Estado Capitalista. Rio de Janeiro: Tempo Brasileiro, 1984.

PISTOR, Katharina. The Code of Capital. How the Law Creates Wealth and Inequality. Princeton: Princeton University Press, 2019.

PRZEWORSKI, Adam. Capitalism and Social Democracy. Studies in Marxism and Social Theory. Cambridge: Cambridge University Press, 1985.

RENNARD, Didier. (2008). L'analyse des politiques publiques aux prises avec le droit, brèves remarques sur un débat. In: L'analyse des politiques publiques aux prises avec le droit. Paris: LGDJ.

RIZZI, Ester Gammardella; BAMBINI, Gustavo. A tarefa de ensinar direito no campo das políticas públicas. Revista Estudos Institucionais, v. 5, n. 3, 2019.

ROSANVALLON, Pierre. La légitimité démocratique. Impartialité, reflexivité, proximité. Paris: Éditions du Seuil, 2018. 
SOUZA, Celina. Estado da arte da pesquisa em políticas públicas. In:

HOCHMAN, Gilberto; ARRETCHE, Marta; MARQUES, Eduardo (Orgs.)

Políticas públicas no Brasil. Rio de Janeiro: Fiocruz, 2007.

TATE, Neal; VALLINDER, Torbjorn. Judicialization and the future of politics and policy. In: TATE, Neal e VALLINDER (orgs.). The Global Expansion of Judicial Power. New York: NYU Press, 1995.

WAHRLICH, Beatriz. A reforma administrativa no Brasil: experiência anterior, situação atual e perspectivas. Revista da Administração Pública, v. 18, n. 1, jan./mar, p. 49-59, 1984.

WERNECK VIANNA, Luiz J. O terceiro poder na Carta de 1988 e a tradição republicana: mudança e conservação. In: BRANDÃO, Gildo M.; RIDENTI, Marcelo; OLIVEN, Ruben. (orgs.) A Constituição de 1988 na vida brasileira. São Paulo: Hucitec-Anpocs, 2018. 